\title{
形状記憶合金を使った宇宙構造物の自動組み立で1 Automatic Construction of Space Truss Structures Using Shape Memory Alloy Elements
}

\author{
田中宏 明*2,*4 名取通弘*3 樋口健 ${ }^{* 3}$ \\ Hiroaki TANAKa, Michihiro NATORI and Ken Higuchi
}

Key Words : Automatic Construction, Shape Memory Alloy, Space Engineering

\begin{abstract}
A concept on automatic construction of space structures by shape memory alloy is proposed. Basic equations of motion of multibody system with shape memory alloy hinge elements are derived from Lagrange equations by consider. ing potential energy of the hinge elements. The possibility of this concept is clarified through the experiment and simulation of free-flying rigid multibody systems. Flexible multibody systems are also examined, and their results are compared with those of rigid multibody systems through numerical simulations. Order of heating of many hinge elements is also studied using genetic algorithms.
\end{abstract}

\section{1.はじめに}

宇宙構造物の建造においては，一般にその資材は地上よ り打ち上げる必要がある。その際搬送効率の向上のため に，分割あるいは折りたたんだ状態で打ち上げ，軌道上で 組み立てや展開を行っている。しかし, 宇宙空間での宇宙 飛行士の作業に際しての安全性の確保は困難なことが多い ため, 資材の自動的な組み立てや展開, さらにシステムレ ベルでの宇宙構造物建造の自動化（ここではそれらを「自 動組み立て」と呼ぶ）が重要となってくる.

形状記憶合金 ${ }^{1)}$ は近年色々と利用されている知的材料 ${ }^{2)}$ であり，宇宙での利用 ${ }^{3)}$ 研究されている。また形状記憶 合金を宇宙で使う際に問題となる変態温度の高温化 ${ }^{4)}$ につ いても研究がなされている.

本研究では形状記憶合金の形状記憶特性を利用した宇宙 構造物の自動組み立ての可能性と，その際起こりうる問題 点について検討する，そこで, 形状記憶合金のヒンジ部を 持つ2次元トラスの無重力下での運動方程式を導き，それ をもとにシミュレーションを行った。この際, リンクの柔 軟性についても考虑した。また実験も行い，それらにより 自動組み立ての可能性を示した. 加熱順序の決定について はGAによる検討を行い，その有効性を示した。

\section{2. 宇宙構造物の自動組み立て}

形状記憶合金を使って宇宙構造物の自動組み立てを行う には，まず構造物の部材同士の結合部を必要な形に形状記 憶処理をほどこした形状記憶合金で作り，構造物を組み立 てる、マルテンサイト変態点以下の温度で収納した後, 軌

\footnotetext{
*1. 平成 11 年 4 月 30 日原稿受理

*2 東京大学大学院

*3 宇宙科学研究所

*4 現在, 三菱電機先端技術総合研究所
}

道上へ搬送し，そこで逆変態点以上に加熱することで形状 記憶合金は元の形に戻り，構造物は自動的に再構成され る。一例として第 1 図に八面体トラスの自動組み立てを示 ఫ.

加熱方法としては太陽光による加熱や形状記憶合金への 通電加熱，他の加熱部材を使った加熱などが考えられる. 太陽光加熱は加熱装置を必要としないが，他の部材の影に なった場合に変形しないなど, 確実性に不安が残る。よっ てここでは通電加熱または他の加熱部材を使った加熱を前 提に考える。

\section{3. 無重力状態での形状記憶合金ヒンジを持つ 剛体多関節構造物の定式化}

3.1 剛体リンクモデルでの基本式 無重力状態での多 関節構造物の定式化にあたり，第 2 図のような回転自由度 を持つジョイントで結合された $n$ 本のリンクにより構成 された多関節構造物を考える。各々の記号は次の通りであ 子.

$$
\begin{aligned}
& m_{i}: \text { リン } i \text { 質量 } \\
& I_{i}: \text { リンク } i \text { その重心に対する慣性モーメント } \\
& r_{i}: \text { リン } i \text { の重心の位置ベクトル } \\
& l_{i}: \text { : シイント } i \text { から } i+1 \text { へのベクトル } \\
& \theta_{i}: \text { リンク } i \text { 慣性座標に対する傾き } \\
& \phi_{i}: \text { : ジイント } i \text { の角度 } \\
& n: \text { リンク数 }
\end{aligned}
$$

形状記憶合金ヒンジ部のポテンシャルエネルギーは、ここ では $\theta=\left(\theta_{1}, \theta_{2}, \cdots, \theta_{n}\right)^{\mathrm{T}}$ の関数として $V(\theta)$ と仮定してお く．そうすると，多関節構造物の運動エネルギーはラグラ ンジュカ程式を用いることで以下のように表すことができ る。 


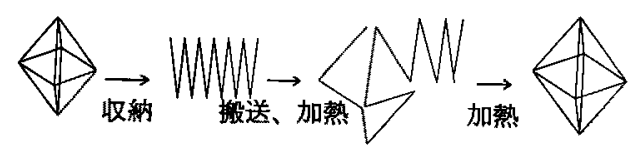

第 1 図 八面体トラスの自動組み立て
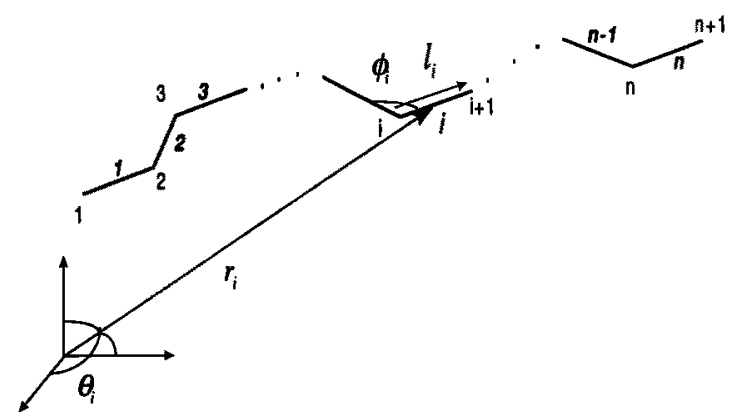

第2図 リンクモデル

$$
\begin{aligned}
& \frac{\mathrm{d}}{\mathrm{d} t} \sum_{j=1}^{n}\left(m_{j} \dot{r}_{j} \cdot \frac{\partial \dot{r}_{j}}{\partial \dot{\theta}_{i}}\right)+I_{i} \ddot{\theta}_{i} \\
& -\frac{\partial V}{\partial \dot{\theta}_{i}}-\left(\sum_{j=1}^{n} m_{j} r_{j} \cdot \frac{\partial r_{j}}{\partial \theta_{i}}-\frac{\partial V}{\partial \dot{\theta}_{i}}\right)=0
\end{aligned}
$$

3.2 形状記憶合金ヒンジ部のポテンシャルエネルギー 続いて形状記憶合金ヒンジのポテンシャルエネルギーを見 積もっていく．まず, 形状記憶合金の応力ーひずみ関係を 次のように仮定する。

1）形状記憶合金の弾性率はマルテンサイト相, オース テナイト相で等しく，Dとする.

2）変態は一定臨界応力のもとで開始し, 応力の変化な く終了するものとする。

3) 逆変態は歪 $\varepsilon=\varepsilon_{0}+\varepsilon_{\mathrm{T}}$ で開始し， $\varepsilon=\varepsilon_{0}$ で終了する とする. ( $\varepsilon_{0}$ は温度の関数である.)

次にこれを元にして形状記憶合金ヒンジ部のポテンシャ ルエネルギーを見積もっていく．幅 $2 h$, 厚さ $2 d$ の形状 記憶合金ヒンジ部の模式図を第 3 図に示す。ポテンシャル エネルギーは $D \varepsilon^{2} / 2$ を中立面から $y$ 方向に積分すること で得られ $\Delta \phi$ の值により 2 通りに分けられる。これはひず み $\varepsilon_{0}$ を超えるかどうかで区別される．ポテンシャルエネ ルギー $V$ は

1) $d>y_{0}$ の場合

$$
\begin{aligned}
\frac{\partial V}{\partial \phi}= & 4 h D L\left(a+\phi-\phi_{\min }\right) \\
& \times\left\{\frac{d}{b^{2}}-\frac{c^{2}}{b^{3}(c+b d)}+\frac{c\left(1+2 \log \frac{c}{c+b d}\right)}{b^{2}}\right\}
\end{aligned}
$$

2) $d<y_{0}$ の場合

$$
\begin{aligned}
\frac{\partial V}{\partial \phi}= & 4 h D L(a+\Delta \phi) \\
& \times\left\{\frac{y_{0}}{b^{2}}-\frac{c^{2}}{b^{3}\left(c+b y_{0}\right)}+\frac{c\left(1+2 \log \frac{c}{c+b y_{0}}\right)}{b^{2}}\right\} \\
& +4 h D L \varepsilon_{0} \frac{b\left(d-y_{0}\right)-c \log \frac{c+b d}{c+b y_{0}}}{b^{2}}
\end{aligned}
$$

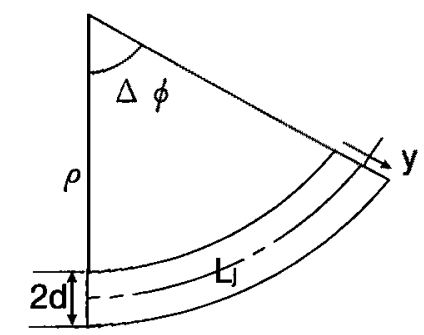

第 3 図 形状記憶合金ヒンジ模式図

ただし

$$
\begin{aligned}
& a=\frac{\varepsilon_{0}\left(\phi-\phi_{\mathrm{M}}\right)}{\varepsilon_{\mathrm{T}}}, \quad b=\frac{\phi-\phi_{\mathrm{M}}}{\varepsilon_{\mathrm{T}}}, \quad c=-L, \\
& y_{0}=\frac{c \varepsilon_{0}}{\Delta \phi+a-b \varepsilon_{0}}
\end{aligned}
$$

である。

また除荷の途中でひずみが増加する場合には，応力ーひ ずみ関係がヒステリシスループの中を通る5,6)ので

$$
\begin{aligned}
\Delta \frac{\partial V}{\partial \phi}= & 4 h D L\left(a+\Delta \phi-\Delta \phi_{\min }\right) \\
& \times\left\{\frac{d}{b^{2}}-\frac{c^{2}}{b^{3}(c+b d)}+\frac{c\left(1+2 \log \frac{c}{c+b d}\right)}{b^{2}}\right\}
\end{aligned}
$$

を加える必要がある。

3.3 柔軟性を考慮したモテル 続いてリンクの柔軟性 を考慮した場合の定式化を行っていく．リンクの柔軟性を 考慮する方法としては固々のリンクをそれぞればねでつな がっている小さなリンクに離散化する方法りを用いる。そ の際，離散化されたリンク同士をつないでいるばねのばね 定数 $K$ 壮

$$
K=D_{\mathrm{L}} I_{\mathrm{z}} / L
$$

となる、またこの場合のポテンシャルエネルギーは

$$
V=K(\Delta \phi)^{2} / 2
$$

であるこここで $D_{\mathrm{L}}$ はリンクの弾性率を， $I_{\mathrm{z}}$ は断面二次モ ーメントを，Lは離散化した小さなリンクの長さを表す。 この $K$ を用いてリンクのポテンシャルエネルギーを考え， 形状記憶合金のポテンシャルエネルギーとあわせて用いる ことで柔軟リンクの運動方程式を表すことができる。

つまり, リンク数 $n$ の弾性リンクモデルを考えた場合, 一つのリンクを $n_{\mathrm{L}}$ 分割したとすると, 全体をリンク数 $n$ $\times n_{\mathrm{L}}$ の剛体リンクモデルと考え, 形状記憶合金ヒンジの 部分では前節のポテンシャルエネルギーを，それ以外では この節のポテンシャルエネルギーを用いることで柔軟性を 考慮できる。

3.4 シミュレーション 前節の式を用いてシミュレー ションを行った．その際の寸法等は以下の通りである.

リンク：リンク数 5

寸法 $10 \times 10 \times 300(\mathrm{~mm})$

材料 檜

ヒンジ：寸法 $0.5 \times 10 \times 42(\mathrm{~mm})$

材料 $\mathrm{Ti}-\mathrm{Ni}$ 形状記憶合金

$\mathrm{Ti}-\mathrm{Ni}$ : 弾性率 $38.5 \mathrm{GPa}$ 
逆変態開始温度 $52^{\circ} \mathrm{C}$

逆変態終了温度 $70^{\circ} \mathrm{C}$

シミュレーションでは第 4 図のような初期の状態から 2 次元トラスを組み立てることを考える。この中から計算結 果より無理のない折りたたみ方になるよう考えていく，以 後, 第 5 図〜第 7 図にそれぞれ Type 1〜Type 3 の場合の

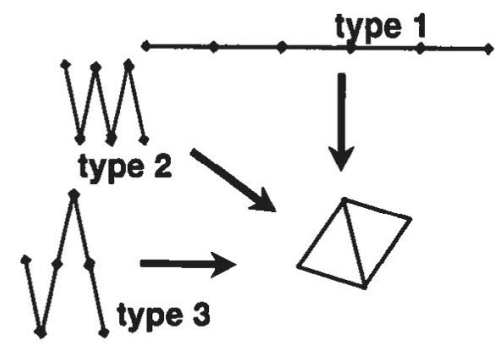

第 4 図 リンク構造物の初期形状

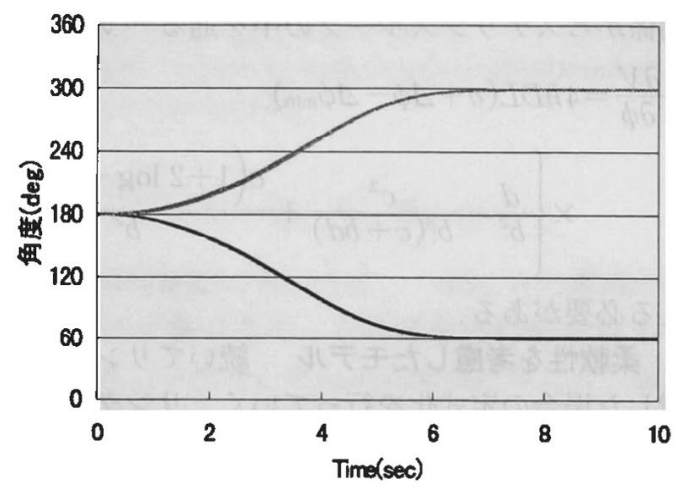

第 5 図 Type 1 の初期状態からの組み立て

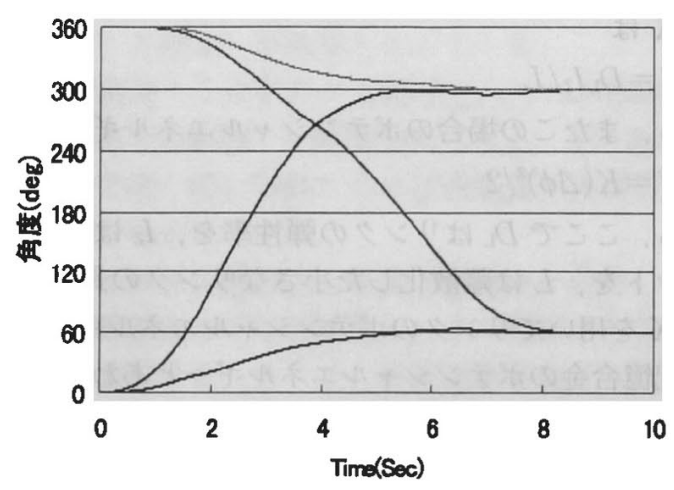

第 6 図 Type 2 の初期状態からの組み立て

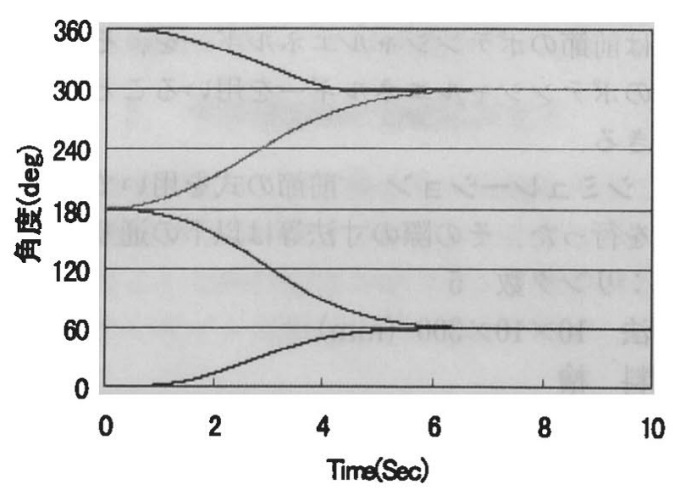

第 7 図 Type 3 の初期状態からの組み立て
各ヒンジ角度の時間に対する変化を示す.

結果より Type 3 の折りたたみ方が組み立ての際のヒン ジの角度変化が小さく，最も無理なく組み立つことが分か る.

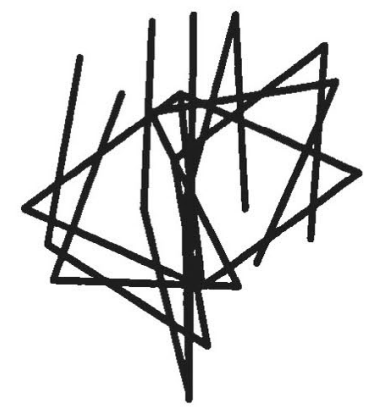

第 8 図 剛体リンクの場合の組み立て

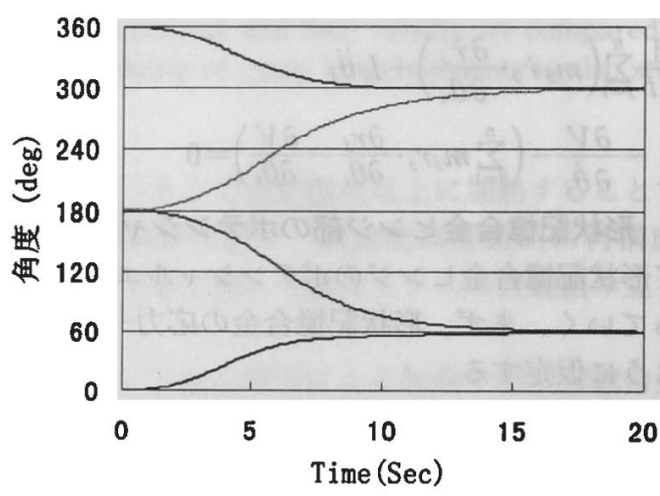

第 9 図 剛体リンクでのヒンジ角度の変化

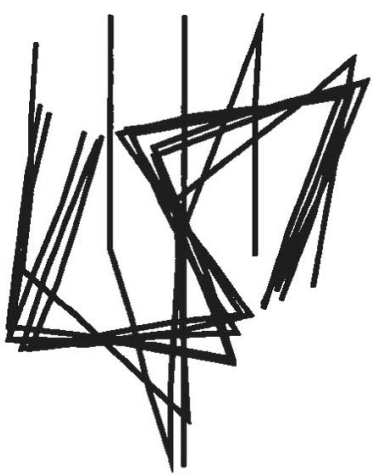

第 10 図 弾性リンクの場合の組み立て

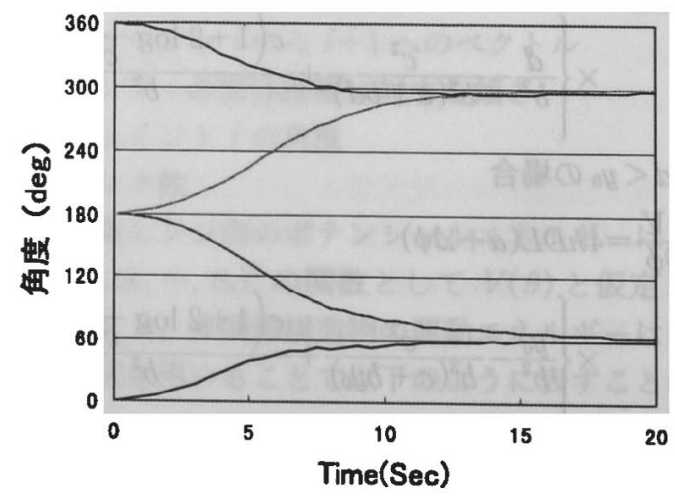

第 11 図 弾性リンクでのヒンシ角度の変化 
続いてリンクの柔軟性を考慮した場合のシミュレーショ ンを行う. 設定はリンクの長さを $4 \times 4 \times 3000(\mathrm{~mm})$ と し，それ以外は前のままである．折りたたみ方は Type 3 を用いる．この場合の剛体リンクの場合と弾性リンクの場 合のシミュレーションを行い,リンクの柔軟性の影響を調 ベる。

剛体リンクの場合の全体の動きを第 8 図に, 各ヒンジ角 度の時間に対する変化を第 9 図に示す。また弾性リンクの 場合の全体の動きを第 10 図に, 各ヒンジ角度の時間に対 する変化を第 11 図に示す. 弾性リンクの場合にはリンク の変形と振動が見られ，組み立て時間が多少長くかかる。

\section{4. リンクモデルの実験}

第 12 図のような実験装置を用いて実験を行った。その 際, 重力の補償には吊り下げ補償法を用い, ヒンジにそっ て取り付けたニクロム線を通電することでヒンジ部を加熱 する.リンクの寸法は $10 \times 10 \times 300(\mathrm{~mm})$ で，それ以外 のパラメータはシミュレーションでの設定と同じとする.

実験結果を第 13 図に示す.シミュレーションの結果と

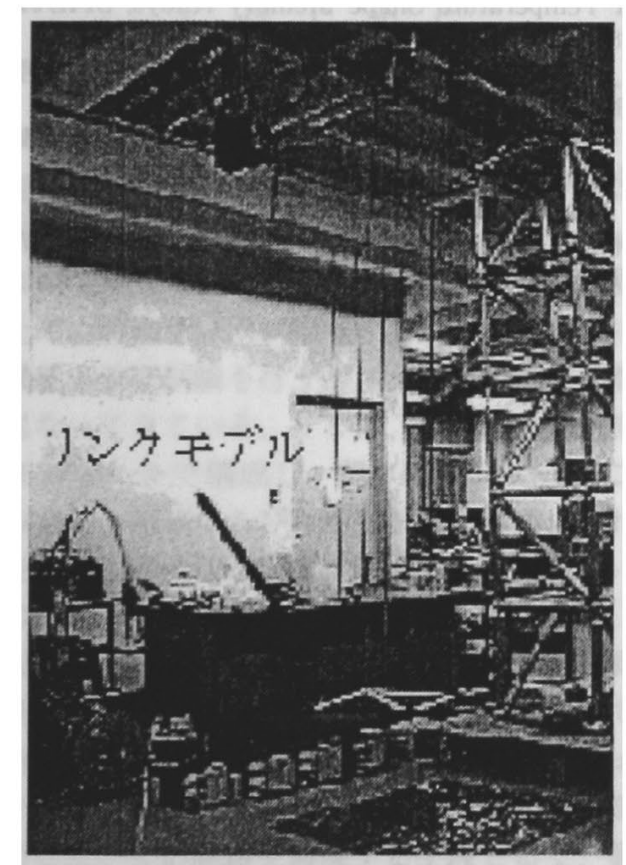

第 12 図 実験装置

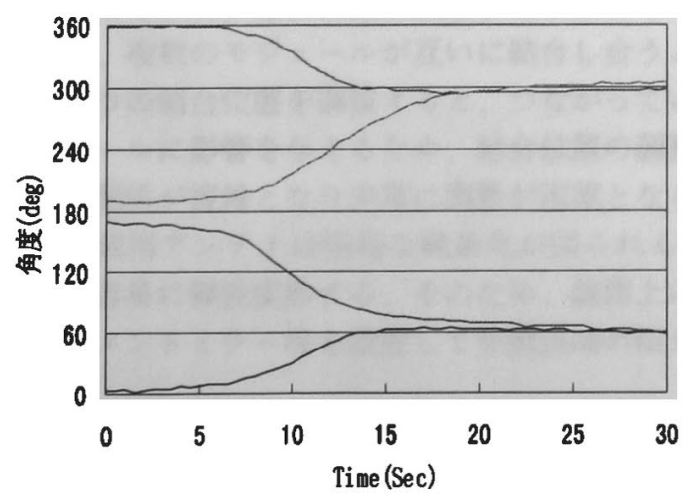

第 13 図 実験でのヒンジ角度の変化
比べ, 組み立てに必要な時間は異なるものの振る舞い自体 は非常に似ていることがわかる。この時間的な違いは，形 状記憶合金ヒンジ部に絶縁体として取り付けたガラスクロ スの抵抗力 (弾性率や減衰率) の影響が大きいためと思わ れる。

\section{GA を使った加熱順序の決定}

5.1 加熱順序 リンク数 5 の場合にはぶつからず組み 立つことが分かったが, リンク数を增やしたり，弾性率な どのパラメータを変化させた場合リンク同士がぶつかって しまう場合がある．そこで全てのヒンジを同時に加熱する のではなく，加熱開始時間を何段階かに分けて行うことで ぶつからないようにすることを考える．その場合どういう 順序で加熱するかが重要だが，その決定に $\mathrm{GA}^{\mathrm{B})}$ を用い る、GA を用いるメリットとしては

・リンク数，弾性率などを変更した場合にも容易に適用て きる

・全探索に比べ計算量が少なくてすむ

ことなどがあげられる。

\section{2 計算の設定＼cjkstart各種設定は以下のとおりである。} 遗伝子

加熱を $t=0, t=0$ での加熱が終了した後の 2 段階で考 え，各ヒンジがどちらのタイミングで加熱するかをならべ たものを遺伝子とする．

パラメータ

集団の数：6（リンク数 7)

10 (リンク数 15)

第 1 表 リンク数 7 での探索結果

\begin{tabular}{|c|c|c|c|c|c|c|}
\hline No & 遺伝子 & 漞 & 漞 & 交叉位置 & 変異位置 & 適合度 \\
\hline 5 & 001000 & 0 & 0 & 0 & 0 & 602 \\
\hline 57 & 000111 & 0 & 0 & 0 & 0 & 122 \\
\hline 55 & 011011 & 0 & 0 & 0 & 0 & 1350 \\
\hline 36 & 110001 & 0 & 0 & 0 & 0 & 536 \\
\hline 31 & 011110 & 0 & 0 & 0 & 0 & 248 \\
\hline 39 & 011001 & 0 & 0 & 0 & 0 & 1502 \\
\hline Time & 1 & Ave & 727 & best & & 122 \\
\hline 31 & 011110 & 57 & 31 & 2 & 0 & 248 \\
\hline 50 & 100011 & 57 & 31 & 2 & 4 & 110 \\
\hline 4 & 110000 & 36 & 31 & 6 & 0 & 536 \\
\hline 63 & 011111 & 36 & 31 & 6 & 0 & 248 \\
\hline 32 & 111110 & 36 & 31 & 2 & 0 & 26 \\
\hline 35 & 010001 & 36 & 31 & 2 & 0 & 302 \\
\hline Time & 2 & Ave & 245 & best & & 26 \\
\hline 51 & 010011 & 31 & 50 & 3 & 0 & 120 \\
\hline 30 & 101110 & 31 & 50 & 3 & 0 & 748 \\
\hline 50 & 100011 & 32 & 50 & 2 & 0 & 110 \\
\hline 28 & 110110 & 32 & 50 & 2 & 3 & 346 \\
\hline 64 & 111111 & 32 & 63 & 6 & 0 & 26 \\
\hline 32 & 111110 & 32 & 63 & 6 & 1 & 26 \\
\hline Time & 3 & Ave & 229 & best & & 26 \\
\hline 24 & 111010 & 64 & 28 & 5 & 4 & 940 \\
\hline 44 & 110101 & 64 & 28 & 5 & 5 & 0 \\
\hline 43 & 010101 & 32 & 51 & 2 & 5 & 0 \\
\hline 31 & 011110 & 32 & 51 & 2 & 0 & 248 \\
\hline 32 & 111110 & 64 & 30 & 4 & 0 & 26 \\
\hline 58 & 100111 & 64 & 30 & 4 & 3 & 200 \\
\hline Time & 4 & Ave & 236 & best & & 0 \\
\hline
\end{tabular}




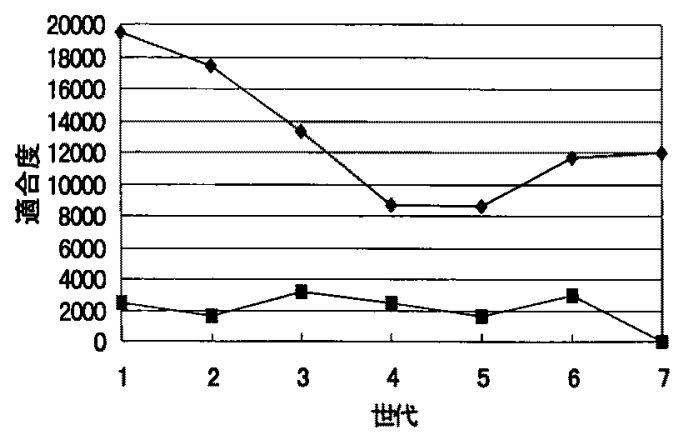

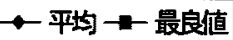

第 14 図 リンク数 15 ての探索結果

交叉確率：0.95

突然変異確率: 0.05

適合度：リンク同士がぶつかっている時間で表し少ない 程よいとする.

シミュレーション設定

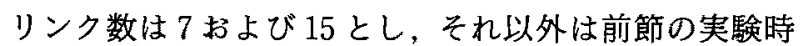
のパラメータを用いる。

5.3 計算の結果 リンク数 7 の場合の結果を第 1 表に 示す. 4 世代目にぶつかり回数が 0 (適合度が 0 : 最適值) になっているのが分かる．何度かの繰り返しでは，ほほ 4 世代目までに解を見つけ出すことができた。

次にリンク数が 15 の場合について加熱順序の探索を行 った. その際の世代数と最適適合度と平均適合度の関係を
第 14 図に示す。この場合では 7 世代目においてぶつから ない加熱順序を求めることができた.

\section{6. 結論}

形状記憶合金を使った宇宙構造物の自動組み立てが可能 であることを研究した．無重力状態で多関節構造物が適切 な初期状態および加熱順序を選ぶことによって衝突なく組 みあがることを数值計算および実験により示した。またり ンクが剛体の場合と，弾性体の場合のシミュレーションを 行いそのダイナミックスの違いが組み立て時の挙動に及ほ す影響を明らかにした。ささらに加熱順序の決定の際に GA を用いることを提案し，効果的であることを示した。

\section{参考 文 献}

1）田中喜久昭, 戸伏壽昭, 宮崎修一：形状記憶合金の機械的性質, 盖 賢堂, 東京, 1993.

2）日本機械学会編：知的複合材と知的適応構造物，養賢堂，東京， 1996.

3）川嶋 聡，片山忠一，杉山吉彦：形状記憶合金ワイヤーによるパ ドルの展開実験, 宇宙構造材料シンポジウム, 1996, pp. 74-77.

4) $\mathrm{Pu}, Z$., Tseng, $\mathrm{H}$. K. and $\mathrm{Wu}, \mathrm{K} . \mathrm{H}$. : An Innovative System of High Temperature Shape Memory Alloys, SPIE 2189, 1994, pp. 289-297.

5）紙田 徹, 松崎雄嗣：形状記憶合金の構成則に関する考察，第 38 回構造強度に関する講演会, 1996, pp. 317-320.

6）紙田 徹, 松崎雄嗣：形状記境合金の応力-歪み-温度関係式, 第 39 回構造強度に関する講演会, 1997, pp. 129-132.

7）松山 剛, 近藤恭平：多リンクモデルよる三次元梁の有限要素 法解析，第 40 回構造強度に関す万講演会, 1998, pp. 157-160.

8）伊庭斉志：遗伝的アルゴリズムの基整，オーム社, 東京, 1994 